Наталья Немич

(D) https://orcid.org/0000-0002-9515-1084

Филиал Военного учебно-научного центра

Военно-воздушных сил

«Военно-воздушная академия

им. профессора Н.Е. Жуковского

и Ю.А.Гагарина» в г. Сызрани

446007, г. Сызрань, Самарская область, ул. Маршала Жукова, 1

nemich.natalya@mail.ru

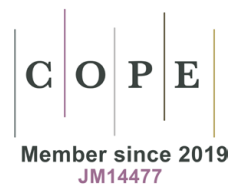

JM14477

\title{
Лексические средства семантики невыразимого в современном газетном дискурсе
}

\author{
Lexical means of the semantics of the inexpressible \\ in modern newspaper discourse
}

\section{Резюме}

В статье рассматриваются лексические средства семантики невыразимого. Невыразимое - это функционально-семантическая категория русского языка, которая служит для передачи невозможности выразить участниками речи объект речи. Динамичное развитие печатных средств массовой информации оказывает огромное влияние на процесс производства и распространения газетных текстов. Актуальность нашего исследования обусловлена тем, что тексты газет являются сегодня одной из самых распространенных форм бытования языка. В современном газетном дискурсе усилилась активная оценочно-воздействующая направленность. Сегодня можно говорить об особой прагматической интенсивности газетного текста, его насыщенности. Одной из смысловых составляющих интенсивности является семантика невыразимого, которая и вызывает интерес. Цель статьи - выявление бытования семантики невыразимого в современных газетных текстах. Принимая во внимание богатый потенциал газетного дискурса как сферы, продуцирующей все новые приемы реализации категории образности, полагаем, что изучение семантических и функциональных свойств невыразимого является актуальной научной задачей. В современном газетном дискурсе авторами используются понятия «невыразимое» и его лексико-семантическая группа как критерий невозможности выразить словами. В текстах газет семантика невыразимого выражается широким набором лексических средств: это имена прилагательные с приставкой, передающей семантику 
отрицания, лишения (невыразимый, непередаваемый, неописуемый, неизреченный и др.), их дериваты: непередаваемо, несказанно, неописуемо, неизъяснимо и др.; глагольные словосочетания: невозможно выразить (передать, сказать); оксюморон: выразить невыразимое; фразеологические единицы: нет слов (чтобы выразить). Наиболее частотны в современном газетном дискурсе в плане передачи значения невыразимого прилагательные невыразимый, непередаваемый и их дериваты, среднечастотны - наречия, грамматические и лексические варианты фразеологизмов-предложений нет слов, не находить слов, словами не передать и глагольные перифразы с отрицанием не могу выразить, не могу передать словами, сказать не могу.

Ключевые слова: семантика, лексические средства, невыразимое, непередаваемое, современный газетный дискурс, маркеры отрицания.

\section{Summary}

The article studies the lexical means of the semantics of the inexpressible. The inexpressible is a functional and semantic category of the Russian language which serves to convey the impossibility of expressing an object of speech by speech participants. The dynamic development of the printed media has a huge impact on the production and distribution of newspaper texts. The relevance of our research lies in the fact that newspaper texts are contemporarily one of the most common forms of language existence. The modern newspaper discourse has been dominated by the evaluative and influencing orientation. Today we can talk about a special pragmatic intensity of newspaper texts and their saturation. One of the semantic components of intensity is the semantics of the inexpressible. The purpose of the article is to identify the existence of unspeakable semantics in modern newspaper texts. Taking into account the rich potential of newspaper discourse as a sphere that produces all new methods of implementing the category of imagery, we believe that the study of the semantic and functional properties of the inexpressible is an urgent research objective. In the modern newspaper discourse, authors use the concept of 'inexpressible' and its lexical-semantic group as a criterion for the impossibility of expressing things in words. In newspaper texts, the semantics of the inexpressible is expressed by a wide range of lexical means: adjectives with a prefix that conveys the semantics of negation, deprivation (inexpressible, indescribable, indescribable, unspeakable, etc.) and their derivatives, such as indescribable, unspeakable, indescribable, inexplicable, etc.; verb phrases that it is impossible to express (convey say); oxymoron as an expression of the inexpressible; phraseological units with no words (to express). The most frequent in the modern newspaper discourse, in terms of the transfer values of unspeakable, are the adjectives unspeakable, indescribable and their derivatives, mid-adverb, grammatical and lexical variants of phraseological units-sentences, such as no words, not finding words, words cannot describe and paraphrased verbs with negation, such a can't tell, not words, I cannot say.

Keywords: semantics, lexical means, inexpressible, indescribable, modern newspaper discourse, markers of negation.

Семантика невыразимого является объектом внимания ученых-философов, ученых-литературоведов, ученых-лингвистов, ученых-теологов в разных странах мира на протяжении многих веков. Вечная проблема «невыразимого» модифицируется в каждую эпоху в конкретном историко-культурном преломлении. Константу «невыразимого» В.В. Дудкин трактует «зазором 
между полнотой, целостностью и непосредственностью и ... визуальной данностью и способностью, а точнее - неспособностью ее адекватно выразить - в данном случае - в слове» (Дудкин, 2012, 101).

Невыразимое - это функционально-семантическая категория особого типа, так как ее значения «накладываются» на значения других категорий. Семантика невыразимого в русском языке служит для передачи невозможности выразить участниками речи объекта речи. Единицы поля невыразимого передают сигнификативную ситуацию невыразимости. Говорящий констатирует, что не может выразить объект речи. Следовательно, понятие «невыразимое» применяется для обозначения отсутствия возможности выражения в силу экстраординарности предмета речи.

В научных трудах, в основном, ученые пишут о средствах передачи семантики невыразимого в своих исследованиях. Так, исследователь Р. Перельштейн пишет о том, что в религии область невыразимого сопряжена с отказом от «внешней мудрости» и устремленностью к «высшему бесстрастию», или безмолвию, каким оно предстает в традиции исихазма, а шире в традиции отрицательного богословия, именуемого апофатизмом» (Перельштейн, 2015, 12). Апофатика, по мнению Р. Перельштейна, присуща природе кинематографа, который пытается «выразить невыразимое, визуализируя отсутствие видимых вещей и присутствие вещей невидимых, какими они предстают в «чистом созерцании» (Перельштейн, 2015, 15).

Е.M. Верещагин, анализируя рече-поведенческие тактики выражения «невыразимого» выясняет, возможно ли в диалоге продвинуться в постижении «непостижимого» и выражении «невыразимого», какие для этого должны быть выполнены условия и какие соответствующие рече-поведенческие тактики способны привести к успеху (Верещагин, 2010, 43).

Е.П. Иванян, исследуя семантику умолчания, говорит о пересечении ее с семантикой невыразимого (Иванян, 2015). Г.С. Сырица определяет специфику семантики невыразимого «особенностями самих денотатов, свойства которых трудно или невозможно передать словами, так и системой языковых средств, их репрезентирующих» (Сырица, 2009, 294).

Специальное исследование, посвященное феномену семантики невыразимого в языке и речи, проведено М.Ю. Михайловой, которая дала характеристику денотативной области семантики невыразимого; осуществила моделирование функциональносемантического поля невыразимого; выявила стилистические приемы передачи семантики невыразимого (прозопографии, экфрасиса и оксюморона) и др. (Михайлова, 2020).

Категория невыразимого в книге О.Э. Мандельштама «Камень» изучалась В.А. Глазыриным и Ю.В. Казариным (Глазырин, Казарин, 2016). М.Ю. Михайлова охарактеризовала семантику невыразимого в «Рассказе о семи повешенных» Л. Андреева (Михайлова, 2016), в творчестве К.Г. Паустовского (Михайлова, 2020). 
Исследуя классический текст, М.В. Михайлова определяет его как игру языка и молчания, где «могущественные слова выявляют бытие того, что собой огораживают, вершат священный танец вокруг невыразимого, чтобы оно стало внятно, оставшись неназванным, не разменянным на медную монету прямых именований» (Михайлова, 2012, 18).

В.В. Дудкин определяет проблему «невыразимого» «как проблему перевода (не в узкоспецифическом, а в общем, культурологическом, смысле): 1) перевод процесса творчества в его результат; 2) перевод визуального (точнее: визуально интеллектуально эмоционально - телесного в их целостности) в вербальное и т. д.» (Дудкин, 2012, 108).

Е.Ф. Гладкая в основе невыразимости видит «острое переживание конфликта между субъективностью, неповторимостью внутреннего, психического содержания и обобщенностью, объективностью языка, между полнотой, целостностью внутреннего знания и конечностью языковых средств выражения» (Гладкая, 2008, 7-8). К лексическим маркерам, указывающим на невербализованные смыслы, Е.Ф. Гладкая относит «слова и выражения со значением невыразимости: несказанный; недосказанность; неназванный; невыразимый; неизъяснимый; для сравнения слов не найду; в словах не опишешь» (Гладкая, 2008, 9).

В.В. Андреев определяет умолчание в качестве намека на невыразимое, несказанное. Исследователь к средствам семантики трудно вербализуемого относит «неопределенные местоимения, наречия, прономинативы и лексические единицы с семой «невыразимое», «неописуемое» (Андреев, 2007, 9).

По мнению Л.А. Горшковой, знание человеком чего-то важного не облегчает возможность это знание выразить. Следовательно, содержанием высказывания с семантикой невыразимого может быть сообщение о знании, которое трудно сформулировать, передать, выразить» (Горшкова, 2005, 22).

М.Ю. Михайлова отмечает, что «семантика невыразимого опирается на грамматическую категорию отрицания, это базовое (основополагающее) значение семантики невыразимого. Все языковые средства передачи семантики невыразимого содержат «грамматику отрицания» (отрицательную частицу не или ни, отрицательное слово нет, отрицательные предлоги без, отрицательные приставки без-/бес-, $a$-, не-» (Михайлова, 2015, 964).

Актуальность нашего исследования обусловлена тем, что тексты газет являются сегодня одной из самых распространенных форм бытования языка. В современном газетном дискурсе усилилась активная оценочно-воздействующая направленность. Сегодня можно говорить об особой прагматической интенсивности газетного текста, его насыщенности. Одной из смысловых составляющих интенсивности является семантика невыразимого, которая и вызывает интерес. Невыразимое - это то, что не поддается выражению или не может быть выражено или объяснено словами, что не может быть рассказано, описано с помощью слов. 
Средства передачи семантики невыразимого в основном содержат в большей или меньшей степени отрицание, например: не могу выразить, невозможно передать, невозможно выразить; или характеризуются наличием отрицательного префикса, например: невыразимый, неописуемый, непередаваемый и их дериваты.

Невыразимое представляет собой функционально-семантическую категорию, которая располагает ядром и периферией средств передачи своего содержания. В ядро поля семантики невыразимого входят отрицательные предложения типа не могу выразить, невозможно передать, невозможно выразить и т.п. и абстрактная лексика с семантикой невыразимого: имена прилагательные с префиксом, передающим семантику отрицания (невыразимылй, непередаваемый, неописуемый) и их дериваты; абстрактные субстантиваты (невыразимое, непередаваемое, неописуемое и др.); наречия (невыразимо, непередаваемо, неописуемо и др.).

Периферия поля включает в себя стилистические маркированные прилагательные несказанный, небывалый, неизреченный и их дериваты; метафоры (не могу найти слов, нет слов) и оксюмороны (выразить невыразимое).

Важно заметить, что граница между ядром и периферией семантики невыразимого и отдельными зонами периферии достаточно нечеткая. Следующим этапом нашего исследования будет деление лексем внутри поля на отдельные микрополя по дополнительным дифференциальным признакам, выявление пересечения микрополей для определения общих зон семантического перехода.

Рассмотрим, как используется семантика невыразимого в современных газетных текстах.

Материалом для исследования послужил современный газетный дискурс: российские федеральные газеты («Известия», «Российская газета») и региональные («Самарская газета», «Волжская коммуна», «Волжские вести»), а также газетный подкорпус Национального корпуса русского языка. Важным критерием отбора материала послужило время его опубликования (с 2000 по 2020 годы). Отбор материала производился методом сплошной выборки.

М.Ю. Михайлова к лексическим средствам поля невыразимого относит «прилагательные с отрицательным префиксом (невыразимый, несказанный, неописуемый, ненареченный и др.), наречия невыразимо, несказанно и т.П., фразеологические выражения слов нет, ни в сказке сказать ни пером напиcamь (описать) и т. п., нечленимые сочетания нечто невыразимое, что-то неописуемое и т.п.» (Михайлова, 2020а, 99).

В текстах газет семантика невыразимого выражается широким набором лексических средств: это имена прилагательные с приставкой, передающей семантику отрицания, лишения (невыразимый, непередаваемый, неописуемый, неизреченный, и др.), их дериваты: непередаваемо, несказанно, 
неописуемо, неизъяснимо и др.; глагольные словосочетания: невозможно выразить (передать, сказать); оксюморон: выразить невыразимое; фразеологические единицы: нет слов (чтобы выразить). Ср.: Безусловно, Греция влечет и морем. У меня не хватает слов, чтобы описать всю его притягательность. Оно здесь необыкновенно красиво и имеет столько колористических оттенков (Волжские вести, 25.12.2015); Невозможнн передать словами, в каких условиях проживали эти дети (Новый регион 2, 10.03.2010); $K$ слову, в темное время суток трасса освещена настолько, что кататься по ней среди огоньков - непередаваемое удовольствие! (Волжские вести, 30.01.2015); Мне кажется, в ту ночь возвращения домой под невыразимо ужасным и невыразимо величественным небом я поняла несколько важных вещеей (Известия, 1.03.2012); Непередаваемый сержантский рык выравнивает строй людей в бельх строительных касках, с палками и арматурой в руках (Комсомольская правда, 4.07.2013).

Средства выражения функционально-семантических значений невыразимого содержат маркеры отрицания (невозможность выразить, описать, передать): Посещение рынков - незабываемая экскурсия, знакомство с ремеслом, творчеством, традициями и мудростью прекрасного узбекского народа. Впрочем, пережстый мною восторг словами не выразить. Нужно все увидеть своими глазами. Поезжайте в Узбекистан! (Волжские вести, 5.06.2015).

Также нами выявлено, что пишущий часто пытается каким-то образом дополнительно охарактеризовать что-то/нечто невыразимое/непередаваемое, чтобы сделать этот объект если не «выражаемым, понятым другими», то хотя бы представляемым в воображении: Tym началось что-то непередаваемое, фантастическое - на наших глазах несколько пуль попало в «губастого», а он продолжал стрелять, не реагируя на эти попадания (Труд-7, 20.07.2005); - Впервые побывал на фестивале красок Холи, эмоции не передать словами! - поделился впечатлениями Иван Исаев. - Жаль, что не ходил раньше: не знал, насколько это весело (Волжские вести, 2.07.2019).

Автор газетной статьи иногда ориентируется на ощущаемое, но трудно передаваемое словами: Уверяю: любые гастрономические фантазии меркнут перед узбекским пловом! Передать его вкус невозможнно. Нужно просто приехать в Ташкент и отведать это блюдо (Волжские вести, 29.05.2015); или вкладывает ориентацию на ощущаемое в речь реципиента: Бывают эмоции, которые не выразить словами, - говорит моя героиня задумчиво. - Но передать чувства все равно хочется. И тогда я делаю это с помощью своих вязаных игрушек (Волжские вести, 13.02.2015).

Лексика с семантикой невыразимого используется по отношению к предметам и явлениям объективной действительности, имеющим и не способным иметь «запах»: Более сложная модель - очищенная от мякоти шкурка половины апельсина заполняется гелем для свечей оранжевого иявта (такой гель можно купить, например, в магазине ИКЕА). Запах от таких 
фруктовых свечек непередаваемый! (Комсомольская правда, 23.12.2002); характеризующими звуки: Командир в новомодном камуфляже «флектарн» издает совершенно непередаваемый звук «ч-ч»- то ли ветка сухая упала, то ли осенний лист (Комсомольская правда, 21.10.2011); И тут я слышу невыразимо нежные звуки, похожие больше на журавлиное курльканье, чем на кваканье наших лягушек (Комсомольская правда, 20.02.2004).

Выявлено, что лексика с семантикой невыразимого используется при характеристике:

- особенностей значимых для человека периодов времени: Около часа длится хореографическая симфония на музыку Малера «Что говорит мне любовь», а кажется, что пролетел один невыразимо прекрасный миг (Известия, 29.03.2012);

- материальных и нематериальных ценностей: «Тут все мое, даже трава», - говорит один из героев фильма, окидыввая взглядом невыразимо прекрасные поля, луга, перелески (Труд-7, 9.11.2005).

- социальных явлений: США осуждают осаду Эль-Кусейра, в ходе которой было убито несказанное число людей (Комсомольская правда, 6.06.2013).

- эмоций, чувств-ощущений: Теперь человек, вчера считавшийся русским (или советским, что не слишком-то отличимо от русского), ощутил себя совершенно и невыразимо одиноким на просторах Вселенной, планеть которой вращаются вокруг американской звезды - главного светила, расположенного, увы, за мириады световых лет от нашей утративщей прошлое и сдавщей в аренду будущее страны (Комсомольская правда, 19.01.2004); Глядишь на Броньку, героиню романа «На острове Буяне», - беспутную, глуповатую, но такую природно мудрую при том бабу, - и невыразимая нежность авторская чуется, и любовь такая, что до рези в глазах (Комсомольская правда, 18.05.2018).

Этим чувствам-ощущениям в определенных ситуациях трудно подобрать слова, выразить свои эмоции, поэтому, демонстрируя свои эмоции, говорящий использует в своей речи слова, содержащие аксиологические оценки, например: Вечером мы легли спать, а ночью очнулись от того, что кто-то нас душил. Уэас был непередаваемый. У нас обеих было ощущение, что мы умираем (Комсомольская правда, 31.07.2006); - В последние годы у нас с мужем появилось особое хобби. Мы стали путешествовать в автобусах по всем странам Европы, - рассказывает моя собеседница. - Побывали практически во всех столииах. Ощущения - непередаваемые! Потом весь год вспоминаем и планируем поездки (Волжские вести, 23.07.2019).

Невыразимое используется в виде субстантиватов с общим значением «обобщенная субстанция». В предложении такие слова выступают в роли подлежащего и дополнения: Подобно бергмановскому оператору Нюквисту, игрой теней, рефлексов, изломом перспективы передает невыразимое: шепоты и крики, спор жизни и смерти (Новая газета, 18.04.2018). 
Авторами газетных текстов элементы невыразимого, непередаваемого, неописуемого употребляются в качестве текстовых синонимов. Ср.: У всех великих групп есть нечто общее, прекрасное и неописуемое, что невозможно передать словами, и что отличает их ото всех остальных (lenta. $\mathrm{ru}$, 5.03.2015).

Как отмечает М.Ю. Михайлова, «происходит некоторое семантическое выветривание, сближение значений данных языковых единиц. В таких случаях правомерно говорить о кластерном бытовании семантик невыразимого, непостижимого» (Михайлова, 2020а, 59).

Причины использования ситуаций категории невыразимое, по мнению М.Ю. Михайловой, следующие: это «низкая языковая компетенция, отсутствие сформированности логического концепта понятия, плохое знание языка, врожденные девиации, психическое или физическое состояние, экстраординарность предмета речи (его инобытие)» (Михайлова, 2017, 177).

Причины ситуации невыразимости способны быть не только объективного, но и субъективного характера. Так, говорящий может на свое усмотрение маркировать ситуацию как невыразимую. Ср.: B ходе проведения мероприятия было задержано и доставлено в отдель внутренних дел 114 граждан, из них 44 несовершеннолетних в возрасте от 1 месяиа до 18 лет. «Невозможно передать словами, в каких условиях проживали эти дети. В хибарах, построенных из фанеры и досок, стояли самодельные печки. Со стороны улищы дома были обтянуты плеткой, а изнутри одеялами...» (Новый регион 2, 10.03.2010).

Пример является стандартной фигурой речи, узуальной гиперболической метафорой. Очевидно, что журналисту на самом деле не трудно найти слова, чтобы охарактеризовать условия проживания детей, например, в домах, не пригодных для жилья, в полной антисанитарии и т. п.

Процесс осуществляется (констатируется невозможность выразить) относительно абстрактного опредмеченного понятия, качества, свойства. Это предмет речи описываемой ситуации невыразимости, точнее, ее предметность, ср.: Поездку эту мы посвятили великим классикам - Тициану и Тинторетто. Каждую базилику украшают творения этих гениальных мастеров. Мы ходили по тем же улочкам, что и они, только веками раньше. Писали те же виды, с тех же мосточков... Как будто мы с этими великими венецианцами стали добрыми соседями ... Такое ощущение - непередаваемо! Причем - в доступе для всех, кто сюда приезжает (Волжские вести, 29.01.2019).

Семантика невыразимого в газетном дискурсе содержит внушительное количество оксюморонов (например, выразить невыразимое), и фразеологических единиц (например, нет слов): Но при всех проблемах (прежде всего драматургической невнятности) авторская анимация продолжает заниматься поиском киноязыка, который мог бы выразить «невыразимое» (Новая газета, 20.03.2018); Многие рассуждают о том, как можно переда- 
вать непередаваемое (Известия, 23.05.2014); «Была разрушена 21 могила советских солдат, которых похоронили на Старом кладбище. Нет слов!» - сказал он. Польская полиция разыскивает вандалов, которые повредили надгробия, рассказал ТАСС пресс-секретарь посольства России в Варшаве Владимир Александров (Коммерсант, 9.10.2018).

Из субстантиватов невыразимое, непередаваемое, несказанное, неописуемое в качестве наиболее общего понятия данной семантики выделяем субстантиват невыразимое. По мнению М.Ю. Михайловой, «он обладает меньшим количеством дифференциальных сем, как и положено доминанте синонимического ряда» (Михайлова, 2020, 58). Семантика невыразимого утверждает невозможность передать мир чувств и отношений, мир внутрителесных ощущений при помощи речи. Отрицая возможность выразить, конституенты поля невыразимого передают эти сложные явления и сферы действительности. Ср.: Не могу выразить словами, как сжалось сердие мое от таких слов великого актера (Труд-7, 10.11.2005). Я не могу выразить словами, что мы чувствуем...(Труд-7, 1.09.2005). А Гусев - это эмочии, непередаваемый, «гусевский» способ произношения слов (Труд-7, 2.06.2008). Ловлю себя на желании говорить о работах Сафронова еще и еще. Но никакие слова не передадут чувств, которые испытываешь от его картин (Волжские вести, 10.04.2015).

В целом заключаем, что в современном газетном дискурсе авторами используются понятия «невыразимое» и его лексико-семантическая группа как критерий невозможности выразить словами в силу экстраординарности предмета речи. Общими для анализируемых значений являются маркеры отрицания, сфера бытования, общие средства выражения: наречия, прилагательные, субстантиваты с отрицательным префиксом, отрицательные синтаксические конструкции.

Наиболее частотны в современном газетном дискурсе в плане передачи значения невыразимого такие лексические средства, как прилагательные невыразимый, непередаваемый и их дериваты, среднечастотны - наречия, грамматические и лексические варианты фразеологизмов-предложений нет слов, не находить слов, словами не передать и глагольные перифразы с отрицанием не могу выразить, не могу передать словами, сказать не могу и др.

\section{БИБЛИОГРАФИЯ}

Андреев, В.В. (2007). Средства выражения семантики умолчания в произведениях 3.Н. Гиппиус: автореф. дисс. ...канд. филолог. наук. Самара.

Верещагин, Е.М. (2010). Несказанное, неизреченное и неизглаголанное. Рече-поведенческие тактики выражения невыразимого. Логический анализ языка. Моно-, диа-, полилог в разных языках и культурах, 43-58. Москва: Индрик. 
Гладкая, Е.Ф. (2008). Языковые маркеры невербализованных смыслов в лирике: автореф. дисс. ...канд. филолог. наук. Москва.

Глазырин, В.А., Казарин, Ю.В. (2016). Категория невыразимого в книге О.Э. Мандельштама «Камень». Новая Россия: традиции и инновации в языке и науке о языке, 317-325. Москва-Екатеринбург: Кабинетный ученый.

Горшкова, Л.А. (2005). Семантика и функиии неопределенных местоимений в прозе Б.К. Зайиева: автореф. дисс. ... канд. филолог. наук. Уфа.

Дудкин, В.В. (2012). «Невыразимое» У Данте, Гете и Достоевского». Евангельский текст в русской литературе XVIII-XX веков: цитата, реминисценция, мотив, сюжет, жанры, ПетрГУ - Петроза водск; Москва.

Иванян, Е.П. (2015). Семантика умолчания и средства ее выражения языке. М.: ФЛИНТА.

Михайлова, М.В. (2012). Эстетика классического текста: автореф. дисс. ... докт. филолог. наук, Санкт-Петербург.

Михайлова, М.Ю. (2015). Семантика невыразимого и смежные явления. Известия Самарского научного центра Российской академии наук, т. 17, № 1(4), 963-966.

Михайлова, М.Ю. (2016). Семантика невыразимого в «Рассказе о семи повешенных» Л. Андреева. Российский гуманитарный журнал, № 5(6), 573-579.

Михайлова, М.Ю. (2016). Семантика невыразимого: узкое и широкое понимание. Филологические науки. Вопросы теории и практики, № 9(63): в 3-х ч. Ч. 1, 128-131.

Михайлова, М.Ю. (2017). Характеристика ситуаџии невыразимости для функиионально-семантической категории. Российский гуманитарный журнал, т. 6, № 2, 174-179.

Михайлова, М.Ю. (2020а). Семантика невыразимого в языке и речи. М.: ФЛИНТА; Самара: СГСПУ.

Михайлова, М.Ю. (2020б). Семантика невыразимого в творчестве К.Г. Паустовского. Поволжский педагогический вестник, т. 8, № 1(26), 88-94.

Ожегов, С.И., Шведова, Н.Ю. (1999). Толковый словарь русского языка. М.: Азбуковник.

Перельштейн, Р. (2015). Видимый и невидимый мир в киноискусстве. СПб.: Центр гуманитарных инициатив.

Сырица, Г.С. (2009). Семантика невыразимого как этнокультурный феномен. Славянские языки и культуры в современном мире: Международный научный симпозиум: Труды и материалы. М.: МАКС Пресс, 294-295.

$$
* * *
$$

Andreev, V.V. (2007). Sredstva vyrazheniya semantiki umolchaniya v proizvedeniyakh Z.N. Gippius: avtoref. diss. ...kand. filolog. nauk. Samara.

Dudkin, V.V. (2012). «Nevyrazimoe» U Dante, Gete i Dostoevskogo». Evangel'skii tekst v russkoi literature XVIII-XX vekov: tsitata, reministsentsiya, motiv, syuzhet, zhanry, PetrGU - Petrozavodsk; Moscow.

Gladkaya, E.F. (2008). Yazykovye markery neverbalizovannykh smyslov v lirike: avtoref. diss. ... kand. filolog. nauk. Moscow.

Glazyrin, V.A., Kazarin, Yu.V. (2016). Kategoriya nevyrazimogo v knige O.E. Mandel'shtama «Kamen'». Novaya Rossiya: traditsii i innovatsii v yazyke i nauke o yazyke, 317-325. Moscow-Yekaterinburg: Kabinetnyi uchenyi.

Gorshkova, L.A. (2005). Semantika i funktsii neopredelennykh mestoimenii v proze B.K. Zaitseva: avtoref. diss. ... kand. filolog. nauk. Ufa.

Ivanyan, E.P. (2015). Semantika umolchaniya i sredstva ee vyrazheniya v russkom yazyke. M.: FLINTA. 
Mikhailova, M.V. (2012). Estetika klassicheskogo teksta: avtoref. diss. ... dokt. filolog. nauk, St. Petersburg.

Mikhailova, M.Yu. (2015). Semantika nevyrazimogo i smezhnye yavleniya. Izvestiya Samarskogo nauchnogo tsentra Rossiiskoi akademii nauk, t. 17, № 1(4), 963-966.

Mikhailova, M.Yu. (2016). Semantika nevyrazimogo v «Rasskaze o semi poveshennykh» L. Andreeva. Rossiiskii gumanitarnyi zhurnal, № 5(6), 573-579.

Mikhailova, M.Yu. (2016). Semantika nevyrazimogo: uzkoe i shirokoe ponimanie. Filologicheskie nauki. Voprosy teorii i praktiki, № 9(63): v 3-kh ch. Ch. 1, 128-131.

Mikhailova, M.Yu. (2017). Kharakteristika situatsii nevyrazimosti dlya funktsional'nosemanticheskoi kategorii. Rossiiskii gumanitarnyi zhurnal, t. 6, № 2, 174-179.

Mikhailova, M.Yu. (2020a). Semantika nevyrazimogo v yazyke i rechi. M.: FLINTA; Samara: SGSPU.

Mikhailova, M.Yu. (2020b). Semantika nevyrazimogo v tvorchestve K. G. Paustovskogo. Povolzhskii peda-gogicheskii vestnik, t. 8, № 1(26), 88-94.

Ozhegov, S.I., Shvedova, N.Yu. (1999). Tolkovyi slovar'russkogo yazyka. M.: Azbukovnik.

Perel'shtein, R. (2015). Vidimyi i nevidimyi mir v kinoiskusstve. SPb.: Tsentr gumanitarnykh initsiativ.

Syritsa, G.S. (2009). Semantika nevyrazimogo kak etnokul'turnyi fenomen. Slavyanskie yazyki i kul'tury v sovremennom mire: Mezhdunarodnyi nauchnyi simpozium: Trudy i materialy, 294-295. M.: MAKS Press.

Vereshchagin, E.M. (2010). Neskazannoe, neizrechennoe i neizglagolannoe. Reche-povedencheskie taktiki vyrazheniya nevyrazimogo. Logicheskii analiz yazyka. Mono-, dia-, polilog v raznykh yazykakh i kul'turakh, 43-58. Moscow: Indrik. 